\title{
Climate Effects on Growth, Body Condition, and Survival Depend on the Genetic Characteristics of the Population
}

\author{
Cristina Romero-Diaz, ${ }^{1, *}$ Merel C. Breedveld, ${ }^{1,2}$ and Patrick S. Fitze ${ }^{1,2,3}$
}

1. Departamento de Biodiversidad y Biología Evolutiva, Museo Nacional de Ciencias Naturales, c/ José Gutiérrez Abascal 2, 28006 Madrid, Spain; and Instituto Pirenaico de Ecología, Avenida Na Sa de la Victoria 16, 22700 Jaca, Spain; 2. Department of Animal Ecology, University of Potsdam, 14469 Potsdam, Germany; 3. Department of Ecology and Evolution, University of Lausanne, Biophore, 1015 Lausanne, Switzerland

Submitted May 19, 2016; Accepted June 5, 2017; Electronically published August 29, 2017

Online enhancements: appendix with two parts. Dryad data: http://dx.doi.org/10.5061/dryad.k8776.

AвSTRACT: Climatic change is expected to affect individual life histories and population dynamics, potentially increasing vulnerability to extinction. The importance of genetic diversity has been highlighted for adaptation and population persistence. However, whether responses of life-history traits to a given environmental condition depend on the genetic characteristics of a population remains elusive. Here we tested this hypothesis in the lizard Zootoca vivipara by simultaneously manipulating habitat humidity, a major climatic predictor of Zootoca's distribution, and adult male color morph frequency, a trait with genome-wide linkage. Interactive effects of humidity and morph frequency had immediate effects on growth and body condition of juveniles and yearlings, as well as on adult survival, and delayed effects on offspring size. In yearlings, higher humidity led to larger female body size and lower humidity led to higher male compared to female survival. In juveniles and yearlings, some treatment effects were compensated over time. The results show that individual responses to environmental conditions depend on the population's color morph frequency, age class, and sex and that these affect intra- and interage class competition. Moreover, humidity affected the competitive environment rather than imposing trait-based selection on specific color morphs. This indicates that species' responses to changing environments (e.g., to climate change) are highly complex and difficult to accurately reconstruct and predict without information on the genetic characteristics and demographic structure of populations.

Keywords: age-structured populations, age class effects, life-history traits, Zootoca vivipara, humidity, color morph frequency.

\section{Introduction}

Climatic and, more generally, environmental conditions can affect individual performance (e.g., growth rate, survival), population dynamics, and life-history evolution (Bjørnstad and Hansen 1994; Lindström 1999). Changes in environmental conditions may potentially destabilize populations (Lindström and Kokko 2002) and increase

* Corresponding author; e-mail: cromero@mncn.csic.es. ORCIDs: Breedveld, http://orcid.org/0000-0002-3198-7683.

Am. Nat. 2017. Vol. 190, pp. 649-662. (C) 2017 by The University of Chicago. 0003-0147/2017/19005-57001\$15.00. All rights reserved.

DOI: $10.1086 / 693780$ their vulnerability to extinction (Lande 1993; Melbourne and Hastings 2008). Population stability depends on, among other factors, genetic diversity, which facilitates adaptation and population persistence (Sgrò et al. 2011; Whiteley et al. 2015; but see Lande and Shannon 1996).

Genetic characteristics of populations, such as genetic diversity per se (i.e., the genetic diversity within species, populations, or subpopulations) or the genotypic frequencies of polymorphisms, may affect the adaptive capacity of populations and species. This is because genetic variation is potentially associated with many traits, including variation in life-history traits (reviewed in McKinnon and Pierotti 2010). For example, in color-polymorphic lizards Uta stansburiana and Zootoca vivipara, the color polymorphism exhibits genome-wide linkage (Sinervo and Svensson 2002), and different genetic morphs have different resource-holding potential (e.g., endurance), morphology, frequency-dependent survival, and frequency-dependent reproductive success (Sinervo and Lively 1996; Sinervo et al. 2008; San-Jose et al. 2014). Therefore, different color morphs may exhibit different fitness in a given environmental condition. Moreover, because morphs differ in competitiveness, different color morph frequencies produce different competitive environments, which affect all individuals of the population. Consequently, a population's response to environmental conditions may depend on its color morph frequency. However, experiments determining whether and how the interaction between color morph frequency and environmental conditions affects important life-history traits and demography are scarce (Bolton et al. 2015). Thus, whether the effects of environmental change on growth, body condition, survival, and performance depend on the genetic characteristics of populations remains ambiguous, and so does their effects on the extinction risk of populations (Lande and Shannon 1996; Araújo et al. 2005; Pertoldi et al. 2007; Sinclair et al. 2010; McMahon et al. 2011; Pacifici et al. 2015).

The effects of environmental change also depend on whether and how an organism is able to cope with a change. 
Organisms may show an immediate response (e.g., Ergon et al. 2001) or a delayed response, or they may not be able to respond and go extinct (Charmantier et al. 2008; Visser 2008; Hoffmann and Sgrò 2011; Bellard et al. 2012). Immediate responses frequently result from plasticity whereby organisms can cope with the changing environment or adapt behaviorally (Charmantier et al. 2008; Bertossa 2011). Delayed responses include (micro)evolutionary adaptation (Visser 2008; Bellard et al. 2012) and delayed life-history effects (Beckerman et al. 2002). The latter may result from environmental effects (e.g., effects of the maternal and/or offspring environment) on the expression of life-history traits (Mousseau and Fox 1998; Lindström 1999) and trade-offs among current and future reproduction (Le Galliard et al. 2008). Delayed life-history effects can also affect individual performance and give rise to cohort effects, including transstage and transgenerational effects, potentially affecting a population's response to changing environments (Benton et al. $2004,2006)$. In summary, several studies suggest that the effects of environmental conditions and environmental change may depend on, among others, the genetic characteristics of the population, age structure, and plasticity, but unambiguous experimental evidence is lacking.

Here, we experimentally tested whether the effects of abiotic environmental conditions on growth, body condition, reproductive success, and survival depend on the population's color morph frequency. We used the common lizard (Zootoca vivipara) as a model species. The common lizard is a highly hydrophilic species, and populations exhibit a pronounced age structure (Avery 1975; Heulin 1985). Adult males exhibit a genetic color polymorphism (San-Jose et al. 2012, 2013; Fitze et al. 2014), and the polymorphism frequency reflects the genetic characteristics of the populationthat is, the genotype frequencies at the morph loci (at the locus or loci contributing to color morph) and all linked loci (Sinervo et al. 2007, 2008). Zootoca vivipara occurrence is strongly associated with humidity (Pilorge 1987; Ceirans 2007; Peñalver-Alcázar et al. 2016), and climate change models predict a global increase in overall precipitation, mean and extreme temperature, and alteration of local precipitation patterns (IPCC 2013). Given the importance of humidity for Z. vivipara, we simulated environmental change by experimentally exposing lizards to different humidity regimes and crossed this treatment with a morph frequency treatment using a $2 \times 3$ design. Before the experiment started, lizards were maintained and clutches were incubated under standardized conditions. Thereafter, lizards were released in seminatural populations (i.e., outdoor populations with natural vegetation, natural food, and climatic conditions, in which lizards were enclosed and protected from predation; e.g., Le Galliard et al. 2005a, 2008; San-Jose et al. 2014) with different humidity conditions and different color morph frequencies. After 1 year, lizards were recaptured for egg lay- ing and quantifying treatment effects on body size, body condition, growth rates, annual survival, clutch size, and phenotypic traits of offspring. In common lizards, population growth is closely linked to survival and fecundity (e.g., Bestion et al. 2015). Body size predicts clutch size (Bauwens 1999), age at maturation, and juvenile survival (Heulin 1985; Le Galliard et al. 2010). Thus, the measured traits are important for life history and the most relevant traits determining population dynamics in $Z$. vivipara. The conducted experimental design and the measured traits allowed testing for immediate treatment effects on released lizards and for delayed effects on the newly hatched offspring.

We predicted (1) significant effects of habitat humidity on growth, body condition, and survival, especially of juveniles and yearlings, because they allocate most of their energy to growth and thus should be particularly susceptible to environmental conditions (Pilorge et al. 1987). If climatic effects depend on the genetic characteristics of the population, we predicted (2) a significant interaction between habitat humidity and adult color morph frequency on individual traits. Moreover, we predicted that (3) interage class competition depends on the humidity and/or color morph frequency and that effects will be most pronounced in the youngest age classes due to resource-based asymmetric competition (Massot et al. 1992). Specifically, we predicted that juveniles will be more affected than yearlings and adults will be the least affected given that dominance interactions are size dependent (Lecomte et al. 1994; San-Jose et al. 2016). Based on previous observational and experimental evidence (Pilorge et al. 1987; Lorenzon et al. 1999, 2001; Le Galliard et al. 2006; Marquis et al. 2008; Bleu et al. 2013), we also predicted (4) delayed treatment effects on the offspring's phenotype - particularly, positive effects of humidity on clutch size and hatchling size, presumably mediated through increased habitat productivity (e.g., more available food) and/or a higher reproductive investment (Le Galliard et al. 2006; Bleu et al. 2013).

\section{Material and Methods}

\section{Model Species}

The common lizard is a small, sexually dimorphic (e.g., females are longer than males, sexes differ in ventral coloration), ground-dwelling lacertid that preferentially inhabits hygrophilic and mesophilic habitats, and its spatial distribution is linked with soil humidity (Braña 1996; PeñalverAlcázar et al. 2016). Zootoca vivipara has a highly permeable skin, which increases the risk of hydric loss (Grenot et al. 1987), and its hydric balance is mainly controlled by environmental factors and behavioral regulation (i.e., by microhabitat selection or use; Grenot and Heulin 1990; Lorenzon et al. 1999). Water availability constrains growth and repro- 
duction (Lorenzon et al. 1999; Le Galliard et al. 2006), litter size (Bleu et al. 2013), juvenile performance (Le Galliard et al. 2010), and reproductive performance (Marquis et al. 2008), including juvenile size at hatching (Lorenzon et al. 2001; Le Galliard et al. 2006; Marquis et al. 2008). The activity period lasts from March to October, and reproduction begins immediately after females emerge from hibernation (Fitze et al. 2010; Breedveld and Fitze 2015). Most individuals attain sexual maturity in their second year of life, and maturation depends on body size rather than age. The observed minimal reproductive body size varies between 40 and $45 \mathrm{~mm}$ (Heulin 1985; Bauwens 1999). Juvenile mortality is considerably high (up to $90 \%$ ), and once survived the first year, average lifespan is 4-5 years in males and 5-6 years in females (Avery 1975). The reproductive system is polygynandrous, and multiple paternity is common (Fitze et al. 2005). Females lay one to three clutches per year (Heulin et al. 1994; Roig et al. 2000; Horváthová et al. 2013), and once the clutch is laid, no parental care is provided. In Pyrenean populations, females lay on average five eggs per clutch (range: 1-9). Adult Z. vivipara are socially dominant over yearlings, adults and yearlings over juveniles, and adult males over adult females (Pilorge et al. 1987; San-Jose et al. 2016).

In the Pyrenean populations, adult males, but not females (Arribas 2009), exhibit ventral color morphs that behave like a single locus with three alleles (white, $w$; yellow, $y$; and orange, $o$; Sinervo et al. 2007). Morphs can be classified using two color scores (namely, $o$ and $w$ score), which account for the number of putative color alleles ( $o$ score: $2=o o ; 1=y o, w o ; 0=y y, w y$, and $w w ; w$ score: $2=$ $w w ; 1=w y, w o ; 0=y y, y o$, and oo; Sinervo et al. 2007). Color morphs differ visually and are determined by differential carotenoid deposition (San-Jose et al. 2012, 2013), which is unaffected by carotenoid ingestion (Fitze et al. 2009; San-Jose et al. 2013), in line with genetic determination of color morphs (Fitze et al. 2014). Male color morphs exhibit alternative behavioral strategies and periodic frequency cycles (Sinervo et al. 2007). Females have whitish bellies and exhibit context-dependent mate choice (Fitze et al. 2010). They choose mate partners to maximize offspring survival under the predominant adult color morph frequency in autumn (Sinervo et al. 2007; Fitze et al. 2014; San-Jose et al. 2014).

\section{Experimental Design}

From May 2009 to June 2011, lizards originally captured from three different sites in the Spanish central Pyrenees (Roncesvalles, Somport, and Formigal, all part of the northeast Spain clade; Milá et al. 2013) were maintained under seminatural conditions in 12 enclosures located at the field station El Boalar near Jaca, Spain (fig. A1; figs. A1-A4 are available online). Enclosures $\left(100 \mathrm{~m}^{2}\right)$ were surrounded by galvanized metal walls and covered by nets, preventing lizards from escaping and avoiding terrestrial and avian predation. Each enclosure contained a patch of natural vegetation, two water ponds, and four stone piles, providing natural food and water as well as basking sites and shelters. Until May 2010, the hydric conditions and the adult male color allele frequencies did not statistically differ among enclosures. Thereafter, lizards were released in enclosures (randomly with respect to the population of origin) attributed to different experimental treatments (see below and fig. A2). In each enclosure, 20 adults (males: $n=8$, females: $n=12$ ), five or six yearlings (males: $n=2$, females: $n=3$ or 4), and 18-20 newborn juveniles were introduced (population size: $n=43-46)$. The adult sex ratio, age structure, and population density were similar to the average found across oviparous populations (Heulin et al. 1997).

Two treatments, adult male color morph frequency (CMF) and humidity treatment, were applied at the population level using a $3 \times 2$ factorial design. The eight adult males released per enclosure (i.e., 16 alleles) matched an allelic proportion as close as possible to $2: 1: 1$ (predominant allele : subdominant allele 1 : subdominant allele 2 ). In four enclosures, orange was the predominant color allele (hereafter, orange predominance $[\mathrm{Op}]$ ); in another four, yellow (Yp) was the predominant allele; and in the remaining four, white was the predominant (Wp) allele (fig. A2). Male color morphs were scored by eye and verified using photographs (for further details, see Sinervo et al. 2007).

Half of the enclosures of each CMF treatment were exposed to high $(\mathrm{H})$ humidity and the other half to low $(\mathrm{L})$ humidity (fig. A2). The level of humidity was manipulated using an automatic irrigation system that uniformly irrigated each enclosure twice a day (i.e., at 9 a.m. and 5:30 p.m.). At each irrigation, enclosures belonging to the $\mathrm{H}$ humidity treatment were sprinkled for $12 \mathrm{~min}$ and those of the $\mathrm{L} \mathrm{hu}-$ midity treatment were sprinkled for $5 \mathrm{~min}$. Each irrigation was split into two shifts (H: 6 and 6 min of irrigation; L: 3 and $2 \mathrm{~min}$ of irrigation). The second shift started 2 and $9 \mathrm{~min}$ ( $\mathrm{H}$ and L humidity, respectively) after the end of the first shift. This procedure guaranteed that in all enclosures 14 min passed between the start and the end of the irrigation, and thus lizards of all treatments were exposed to the same treatment length. From May 2009 to May 2010, the humidity regime was between the $\mathrm{L}$ and $\mathrm{H}$ level of the humidity treatment: each enclosure was sprinkled for $8 \mathrm{~min}$ in the morning and $5 \mathrm{~min}$ in the afternoon.

The humidity of the enclosures without irrigation is below the common lizard's natural humidity requirements, allowing for humidity manipulation within the species' natural range. The simulated $\mathrm{H}$ and $\mathrm{L}$ levels conformed to the highest and lowest 10-15th percentile of the humidity range found in natural populations of the Pyrenees (Peñalver- 
Alcázar et al. 2016). In every enclosure, the humidity level was periodically measured (in June, July, August, April, and May) by taking five soil core samples of identical volume from each enclosure and calculating average soil moisture content using a gravimetric method: mass $_{\text {wet }}-$ mass $_{\text {dry }}$. Measurements of soil humidity included natural precipitation, and it was significantly different between humidity treatments in all occasions (all $P<.05$ ). All lizards were individually marked by toe clipping, weighted to the nearest milligram, and measured to the nearest millimeter. Lizards were randomly distributed among treatments (except with respect to adult male color morph), and there were no significant initial differences in snout-to-vent length (SVL) or body condition (BC; the residuals from the regression between body size and weight) among treatments and experimental populations (all $P>.360$ ).

\section{Measurement of Growth, Body Condition, and Survival}

After June 2010, lizards were recaptured during two capturerecapture sessions (in August 2010 and September 2010), each consisting of three consecutive days of intensive captures with equal effort across time and enclosures. All captured individuals were identified, measured for SVL, weighted, photographed, and released back at the exact capture location the following morning. From May 23rd to June 8th, 2011, the enclosures were completely emptied and captured individuals were maintained in the laboratory. We recorded individual growth rate, SVL, and BC at the end of the study, along with annual survival.

\section{Measurement of Reproductive Traits}

All lizards were housed under the same standardized conditions in the laboratory. They were kept individually in terraria $(20 \mathrm{~cm} \times 15 \mathrm{~cm} \times 15 \mathrm{~cm})$ containing a shelter, a water pond, a rock for basking, and peat soil as substrate. Light and heat were provided by a $40 \mathrm{~W}$ bulb following a $12 \mathrm{~L}: 12 \mathrm{D}$ photoperiod. Ultraviolet (UV) lamps provided UVB and UVA for $2 \mathrm{~h}$ per day (12 a.m.-2 p.m.) to facilitate calcium metabolism (San-Jose et al. 2014). Water was available ad lib., and prey items Galleria mellonella, Acheta domestica, or Lumbricus terrestris were provided every other day. Terraria of females were inspected twice a day for laid clutches. On laying, clutch size (i.e., the number of eggs) and laying date were recorded, and laid clutches were thereafter incubated individually in a constantly humid atmosphere at $21^{\circ} \mathrm{C}$ during the day (from 9 a.m. to 9 p.m.) and $19^{\circ} \mathrm{C}$ during the night (Heulin et al. 1997). On the day of hatching, offspring sex (determined by ventral scale count; Lecomte et al. 1992), SVL, tail length (to the nearest millimeter), and body mass (to the nearest milligram) were recorded.

\section{Statistics}

Statistical analyses were performed in R version 2.15.2 using packages nlme (Pinheiro et al. 2013) and lme4 (Bates et al. 2013). Growth, body condition, and survival were analyzed for each age class (juveniles, yearlings, adults) and/or time period (release-August, August-September, SeptemberJune) using linear mixed models. To test for significant differences among age classes or time periods (i.e., treatment $\times$ age class or treatment $\times$ time period interactions), models including either all age classes or all time periods were run (table 1).

Humidity and CMF treatments, sex, and all first-order interactions were modeled as fixed effects, and initial SVL (ISVL; for juveniles: the SVL at hatching; for yearlings and adults: the SVL at the beginning of the experiment) or initial body condition (IBC) were modeled as covariates, the latter only in BC analyses. Enclosure ID and, in models on juveniles, mother ID nested within enclosure ID were modeled as random effects. Hatching date was included as a covariate in the analyses of juvenile and offspring SVL, BC, and tail length at hatching.

Growth rate was defined as the difference in SVL between two capture events divided by the number of days passed ( $\Delta$ SVL/ $\Delta$ Time; e.g., Sorci et al. 1996; Clobert et al. 2000; Le Galliard et al. 2010), excluding the number of days spent in hibernation (from November 1st to March 1st; e.g., Mugabo et al. 2010). "Final SVL" refers to the SVL and "final $B C$ " to the $\mathrm{BC}$ reached at the end of the study (June 2011; i.e., during the reproductive season). In the analyses of final SVL and final BC, "time" accounted for the total time spent inside the populations from release to recapture. Relative clutch size (Rclsize; the residuals of the regression of clutch size on female SVL), a measure of a female's reproductive effort (Massot et al. 2011), was added as a covariate in offspring models, accounting for female body size-independent differences in clutch size. Offspring sex ratio was calculated as the number of male hatchlings divided by the number of hatchlings.

Two adjacent enclosures suffered abnormally high mortality due to invasion of terrestrial predators, and within 1 month only a few individuals remained alive (four out of 43 and five out of 43, respectively). Consequently, we excluded both populations from the analyses. Offspring of undetermined sex (i.e., equivocal sex attribution) were excluded from offspring analyses $(n=37)$. The average recapture probability of surviving yearlings and adults was $87 \%$ and for juveniles was $90 \%$. Thus, annual survival probability was analyzed using generalized linear mixed-effects models with binomial error distribution and a logit link. This model included the same parameters as the abovedescribed models. To test whether treatment-induced survival differences resulted from treatment effects on individ- 
Table 1: Summary of treatment effects on measured traits of common lizards

\begin{tabular}{|c|c|c|c|c|c|}
\hline Trait and treatment & All time periods & Release-August & August-September & September-June & Direction \\
\hline \multicolumn{6}{|l|}{ Juvenile growth: } \\
\hline $\mathrm{CMF}$ & $\mathrm{S}^{\mathrm{ab} * *}$ & $S^{\mathrm{b} * * * *}$ & NS & $\mathrm{S}^{\mathrm{b} * * *}$ & \multirow[t]{2}{*}{ Fig. $2 A$} \\
\hline Humidity & $\mathrm{S}^{\mathrm{ab} * *}$ & $\mathrm{~S}^{\mathrm{b} * * * *}$ & $S^{*}$ & $\mathrm{~S}^{\mathrm{b}^{* * * *}}$ & \\
\hline \multicolumn{6}{|l|}{ Yearling growth: } \\
\hline $\mathrm{CMF}$ & $\mathrm{S}^{\mathrm{ac} *}$ & $S^{*}$ & $\mathrm{~S}^{\mathrm{c} * *}$ & NS & \multirow[t]{2}{*}{ Fig. $2 B, 2 C$} \\
\hline Humidity & $\mathrm{S}^{\mathrm{ac} *}$ & NS & $\mathrm{S}^{\mathrm{c}^{*}}$ & NS & \\
\hline \multicolumn{6}{|l|}{ Adult growth: } \\
\hline $\mathrm{CMF}$ & NS & NS & NS & $\mathrm{S}^{\mathrm{c}^{*}}$ & \multirow[t]{3}{*}{ In text } \\
\hline \multirow[t]{2}{*}{ Humidity } & NS & NS & NS & NS & \\
\hline & All ages & Juveniles & Yearlings & Adults & \\
\hline \multicolumn{6}{|l|}{ Final SVL: } \\
\hline $\mathrm{CMF}$ & NS & NS & NS & NS & \multirow[t]{2}{*}{ Fig. 1} \\
\hline Humidity & $\mathrm{S}^{\mathrm{cd} *}$ & NS & $\mathrm{S}^{\mathrm{c} * *}$ & NS & \\
\hline \multicolumn{6}{|l|}{ Final BC: } \\
\hline $\mathrm{CMF}$ & $\mathrm{S}^{\mathrm{bd} * * *}$ & $\mathrm{~S}^{\mathrm{b} * *}$ & $\mathrm{~S}^{* *}$ & NS & \multirow[t]{2}{*}{ Fig. 3} \\
\hline Humidity & $\mathrm{S}^{\mathrm{bd} * *}$ & $\mathrm{~S}^{\mathrm{b} * *}$ & NS & NS & \\
\hline \multicolumn{6}{|l|}{ Survival: } \\
\hline $\mathrm{CMF}$ & $\mathrm{S}^{\mathrm{bd} *} / \mathrm{S}^{\mathrm{c} * *}$ & $\mathrm{~S}^{\mathrm{c} * *}$ & $S^{*}$ & $\mathrm{~S}^{\mathrm{b}^{*}}$ & \multirow[t]{2}{*}{ Fig. 4} \\
\hline Humidity & $S^{\mathrm{bd}^{*}} / \mathrm{S}^{\mathrm{c} * *}$ & NS & NS & $\mathrm{S}^{\mathrm{b}^{*}} / \mathrm{S}^{\mathrm{c}^{*}}$ & \\
\hline
\end{tabular}

Note: Shown are the results of models including all time periods or age classes and models for each time period and/or age class separated. Significant (S) and nonsignificant (NS) treatment effects are reported. Significant interactions are indicated by superscripts, and the location of the direction of the effects is provided. $\mathrm{BC}=$ body condition; $\mathrm{CMF}=$ color morph frequency; $\mathrm{SVL}=$ snout-to-vent length.

a Interaction with time period.

${ }^{\mathrm{b}}$ Interaction between treatments.

c Interaction with sex.

${ }^{\mathrm{d}}$ Interaction with age class.

${ }^{*} P<.05$.

${ }^{* *} P<.01$.

${ }^{* * * * *} P<.001$.

ual morphs, we ran an additional model including male color morph (i.e., $o$ and $w$ scores).

Model simplification was performed following Zuur et al. (2009), and likelihood ratio tests were used to test parameter significance. In the minimal adequate model, the significance of the main effects was tested using ANOVA type III tests. $P$ values for random effects were calculated by taking into account that the null hypothesis lies on the boundary of the parameter space (i.e., that the variance is zero; Zuur et al. 2009). In all Gaussian models, the assumptions of independence, normality, and homoscedasticity were verified on the residuals. In some models, heteroscedasticity existed and was taken into account by specifying a varIdent structure. All non-Gaussian models were tested for overdispersion, and no evidence for overdispersion existed. For significant factors containing more than two groups, post hoc tests were performed using pairwise contrasts, and HolmBonferroni corrections were applied to account for multiple comparisons (Holm 1979). The significance level was set at $P=.05$, and estimates \pm SE are provided. All data from this study are deposited in the Dryad Digital Repository: http://dx.doi.org/10.5061/dryad.k8776 (Romero-Diaz et al. 2017).

\section{Results}

Treatment Effects on Growth, Body Condition, and Survival

Effects on Body Size and Growth. Final SVL was significantly affected by a three-way interaction between humidity, sex, and age class $\left(\chi_{2}^{2}=8.38, P=.015\right.$; table 1$)$, and it positively correlated with ISVL $\left(\chi_{1}^{2}=76.29, P<.001\right)$. The interaction between humidity and sex was significant only in yearlings (fig. 1). No other effects were found $(P \geq .120)$.

Juveniles. Neither treatment (table 1) nor sex significantly affected juvenile final SVL (table A1; tables A1-A5 are available online). ISVL and time inside the enclosure positively correlated with final SVL $\left(\chi_{1}^{2}=6.05, P=.014\right.$ and $\chi_{1}^{2}=11.11, P<.001$, respectively). There was a significant interaction between humidity, CMF, and time period on juvenile growth rate $\left(\chi_{4}^{2}=16.65, P=.002\right.$; table 1$)$. 


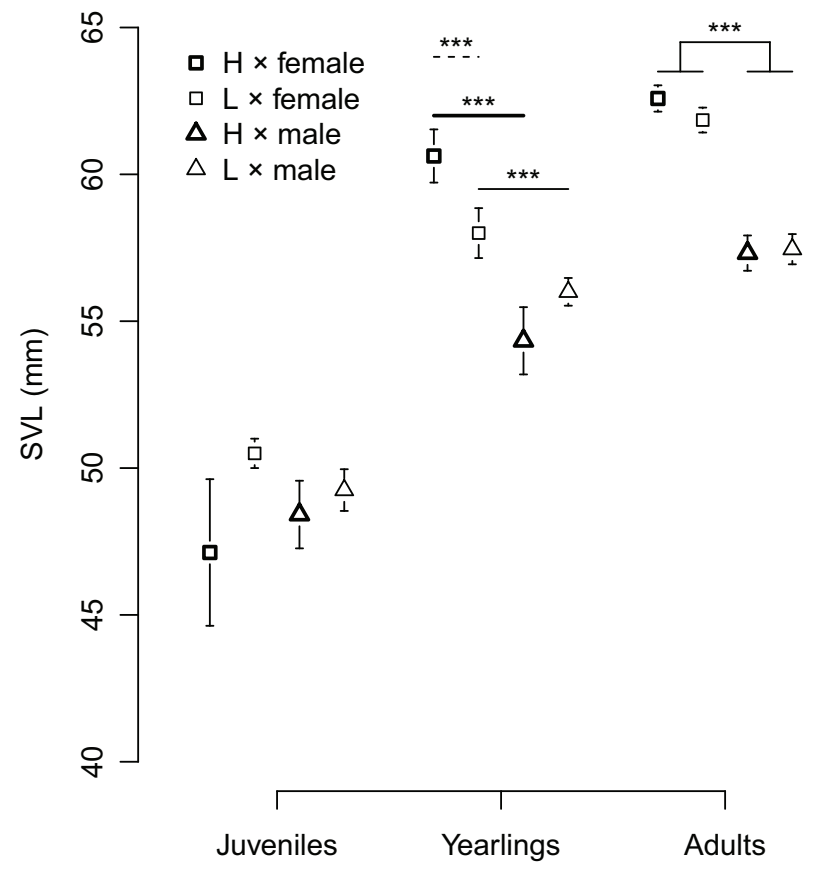

Figure 1: Final snout-to-vent length (SVL) of juveniles, yearlings, and adults by humidity treatment (H: high humidity; L: low humidity) and sex. Means \pm SE are given. Horizontal bars depict main effects (i.e., sex differences) or post hoc contrasts, and asterisks indicate statistical significance: for three asterisks, $P<.001$.

From release to August and from September to June, an interaction humidity $\times$ CMF significantly affected growth rate (table 2), showing that individuals belonging to different CMF treatments responded differently to humidity (see fig. $2 A$ ). Growth rate differences from release to August were balanced by the differences from September to June, leading to no treatment effects on final SVL (table A1; for more details see appendix, pt. A, sec. 1; the appendix is available online). In addition, juveniles grew faster from August to September in L compared to H humidity (table 2 ).

Sex and hatching date effects on juvenile growth rate differed among time periods (table A2). Males grew significantly faster than females from release to August, while females grew faster than males from September to June (table 2). Hatching date negatively correlated with growth rate from release to August, but it positively correlated from September to June (table 2). In both cases, the opposing growth patterns led to no significant differences in juvenile final SVL (fig. 1).

Yearlings. Yearling final SVL was significantly affected by an interaction between humidity and $\operatorname{sex}\left(\chi_{1}^{2}=8.46\right.$, $P=.004$; fig. 1). Females in $\mathrm{H}$ humidity had larger final SVL than females in L (post hoc: $\chi_{1}^{2}=15.49, P<.001$ ), while males were unaffected. As in juveniles, ISVL positively correlated with final SVL $\left(\chi_{1}^{2}=24.23, P<.001\right)$.
There was a significant interaction between humidity, sex, and time period $\left(\chi_{2}^{2}=7.95, P=.019\right.$; table 1$)$ on yearling growth rate. Humidity effects differed between sexes only from August to September (table 2; fig. 2B). Females in $\mathrm{H}$ humidity grew faster than females in $\mathrm{L}$, while no differences existed in males. There was also a significant interaction between CMF, sex, and time period on growth rate (table 1). The interaction between CMF and sex affected growth rate only from August to September (table 2; fig. 2C). In Yp populations, females grew faster than males (post hoc: $\chi_{1}^{2}=7.61, P=.017$ ), while in Wp populations, males grew faster than females. In contrast, from release to August, females in Wp populations grew faster than males (fig. 2C). Thus, growth differences from release to August were balanced by growth differences from August to September, leading to no CMF $\times$ sex effect on final SVL (for further details, see appendix, pt. A, sec. 2). Moreover, CMF affected growth rate from release to August (table 2). Yearlings in Op populations grew faster than yearlings in $\mathrm{Wp}$ populations $(Z=2.96, P=.009$; fig. $2 C)$, and this difference was compensated by slightly higher growth rates of Wp compared to Op populations from $\mathrm{Au}-$ gust to September, leading to no CMF effect on final SVL (table 1).

Finally, there was also a significant three-way interaction between humidity treatment, ISVL, and time period on growth rate (table A3). From release to August and from September to June, the correlation was more negative in $\mathrm{L}$ than in $\mathrm{H}$ humidity (although humidity $\times$ ISVL was not statistically significant), while from August to September it was significantly more negative in $\mathrm{H}$ humidity (table 2), leading to a nonsignificant humidity $\times$ ISVL interaction on final SVL (table A1).

Adults. In adults, we found no significant treatment effects on final SVL (all $P \geq .122$; table 1). Final SVL of males was shorter than that of females $\left(\chi_{1}^{2}=28.90, P<.001\right.$; fig. 1$)$, and it positively correlated with ISVL $\left(\chi_{1}^{2}=57.97\right.$, $P<.001)$. Neither treatments nor their interaction significantly affected adult growth rate (table 1). However, a CMF $\times$ sex interaction affected growth from September to June; females in Yp populations grew faster than females in Op $\left(\chi_{1}^{2}=6.83, P=.045\right)$ and $\mathrm{Wp}\left(\chi_{1}^{2}=9.12, P=\right.$ $.015)$ populations. Growth rate was also affected by the interactions between sex and time period $\left(\chi_{2}^{2}=30.45, P<\right.$ $.001)$ and ISVL and time period $\left(\chi_{2}^{2}=62.58, P<.001\right)$. Females grew faster than males from release to August $\left(\chi_{1}^{2}=45.57, P<.001\right)$ but not in the other two periods (August-September: $\chi_{1}^{2}=45.57, P=.294$; SeptemberJune: $\left.\chi_{1}^{2}=1.44, P=.229\right)$. In turn, ISVL negatively correlated with growth rate from release to August and from August to September $\left(\chi_{1}^{2}=98.98, P<.001\right.$ and $\chi_{1}^{2}=$ 9.53, $P<.001$, respectively) but not from September to June. 
Table 2: Treatment effects on juvenile and yearling growth rates $\left(\mathrm{mm} \mathrm{day}^{-1}\right)$ measured in three time periods: release-August, AugustSeptember, September-June

\begin{tabular}{|c|c|c|c|c|c|c|c|c|c|}
\hline \multirow[b]{2}{*}{ Age class and effect } & \multicolumn{3}{|c|}{ Release-August } & \multicolumn{3}{|c|}{ August-September } & \multicolumn{3}{|c|}{ September-June } \\
\hline & $\chi^{2}$ & $\mathrm{df}$ & $P$ & $\chi^{2}$ & $\mathrm{df}$ & $P$ & $\chi^{2}$ & $\mathrm{df}$ & $P$ \\
\hline \multicolumn{10}{|l|}{ Juveniles: } \\
\hline \multicolumn{10}{|l|}{ Fixed: } \\
\hline $\mathrm{CMF}$ & 21.07 & 2 & $<.001$ & 5.79 & 2 & .055 & 132.30 & 2 & $<.001$ \\
\hline Humidity & 25.99 & 1 & $<.001$ & 4.88 & 1 & .027 & .170 & 1 & .680 \\
\hline CMF $\times$ humidity & 17.63 & 2 & $<.001$ & 1.08 & 2 & .634 & 19.65 & 2 & $<.001$ \\
\hline Sex & 6.86 & 1 & .009 & .20 & 1 & .991 & 12.52 & 1 & $<.001$ \\
\hline $\mathrm{CMF} \times \operatorname{sex}$ & .32 & 2 & .851 & .19 & 2 & .926 & NP & NP & NP \\
\hline Humidity $\times$ sex & 1.30 & 1 & .255 & .27 & 1 & .556 & 1.98 & 1 & .159 \\
\hline ISVL (mm) & .62 & 1 & .432 & 1.05 & 1 & .380 & 16.01 & 1 & $<.001$ \\
\hline Hatching date (days) & 41.85 & 1 & $<.001$ & .70 & 1 & .268 & 21.05 & 1 & $<.001$ \\
\hline \multicolumn{10}{|l|}{ Random: } \\
\hline Enclosure ID & .26 & 2 & .438 & 1.69 & 2 & .214 & 2.08 & 2 & .177 \\
\hline Mother ID in enclosure ID & .32 & 1 & .286 & .76 & 1 & .191 & $<.01$ & 1 & .500 \\
\hline \multicolumn{10}{|l|}{ Yearlings: } \\
\hline \multicolumn{10}{|l|}{ Fixed: } \\
\hline CMF & 7.45 & 2 & .024 & 1.57 & 2 & .455 & 3.67 & 2 & .160 \\
\hline Humidity & .24 & 1 & .625 & 3.89 & 1 & .048 & 2.27 & 1 & .132 \\
\hline CMF $\times$ humidity & 1.41 & 2 & .494 & 5.43 & 2 & .066 & 1.53 & 2 & .464 \\
\hline Sex & 18.50 & 1 & $<.001$ & 2.76 & 1 & .096 & .61 & 1 & .434 \\
\hline $\mathrm{CMF} \times \operatorname{sex}$ & $<.01$ & 2 & .998 & 9.24 & 2 & .010 & 2.250 & 2 & .325 \\
\hline Humidity $\times$ sex & .11 & 1 & .735 & 4.51 & 1 & .034 & $<.01$ & 1 & .948 \\
\hline ISVL $(\mathrm{mm})$ & 43.14 & 1 & $<.001$ & 4.49 & 1 & .034 & 7.29 & 1 & .007 \\
\hline Humidity $\times$ ISVL & .35 & 1 & .555 & 4.54 & 1 & .033 & 2.38 & 1 & .123 \\
\hline \multicolumn{10}{|l|}{ Random: } \\
\hline Enclosure ID & .17 & 2 & .458 & $<.01$ & 2 & .500 & $<.01$ & 2 & .500 \\
\hline
\end{tabular}

Note: Results of likelihood ratio tests are shown, and the minimal adequate model is depicted in boldface. Plain values correspond to the values before backward elimination. NP indicates when it is not possible to model since not enough juveniles survived in each of the parameter combinations. $\mathrm{CMF}=$ color morph frequency; ISVL = initial snout-to-vent length.

Effects on Body Condition. Final BC was affected by a significant three-way interaction between humidity, CMF, and age class $\left(\chi_{4}^{2}=14.01, P=.007\right.$; table 1 ; fig. 3$)$. The interaction between treatments affected juveniles $\left(\chi_{2}^{2}=12.81\right.$, $P=.002)$ but not yearlings or adults $(P \geq .230$; table 1$)$. Final BC was also affected by an interaction between sex and age class $\left(\chi_{2}^{2}=13.82, P=.001\right)$ and an interaction between time spent in the enclosure and age class $\left(\chi_{4}^{2}=\right.$ $6.50, P=.039)$, and it was positively correlated with IBC $\left(\chi_{1}^{2}=6.23, P=.013\right)$. Final BC differed between sexes in juveniles but not in yearlings or adults (all $P>.281$ ), and time in the enclosure negatively correlated with final BC of yearlings $\left(\chi_{1}^{2}=5.09, P=.024\right)$ but not of juveniles or adults (all $P>.445)$.

Juveniles. In $\mathrm{Wp}$ populations, juveniles in $\mathrm{H}$ humidity showed higher final BC than those in $\mathrm{L}$ (post hoc: $\chi_{1}^{2}=$ 7.10, $P=.023$; fig. 3). In Yp populations, juveniles tended to have higher $\mathrm{BC}$ in $\mathrm{L}$ than in $\mathrm{H}$ humidity $\left(\chi_{1}^{2}=4.19\right.$, $P=.081)$, while Op populations were unaffected $(P=$ .270). Moreover, in $\mathrm{H}$ humidity, final $\mathrm{BC}$ of juveniles of Op populations was significantly higher than that of $\mathrm{Wp}$ populations and tended to be higher than Yp populations $\left(\chi_{1}^{2}=7.41, P=.039\right.$ and $\chi_{1}^{2}=6.02, P=.071$, respectively; fig. 3). In L humidity, juveniles of $\mathrm{Wp}$ populations had lower body condition than those of Yp and Op populations, but these differences were not statistically significant (all $P \geq .134$ ). In addition, females had lower final BC than males $\left(\chi_{1}^{2}=16.41, P<.001\right)$.

Yearlings. CMF significantly affected yearling final BC $\left(\chi_{2}^{2}=10.99, P=.004\right)$. In Op and Yp populations, final $\mathrm{BC}$ was higher than in Wp populations (post hoc: $Z=4.27$, $P<.001$ and $Z=3.82, P<.001$, respectively; fig. 3 ). There was a significant interaction between humidity, CMF, and time period on body condition change (table A4), revealing different humidity $\times$ CMF effects in different time periods. Given the absence of an interaction between humidity and CMF on final BC $(P=.230)$, interactive treatment effects were compensated over the course of the experiment.

Effects on Survival. Survival was affected by a significant interaction between humidity, CMF, and age class $\left(\chi_{4}^{2}=\right.$ 10.173, $P=.038$; table 1 ; fig. 4 ). Post hoc contrasts showed 

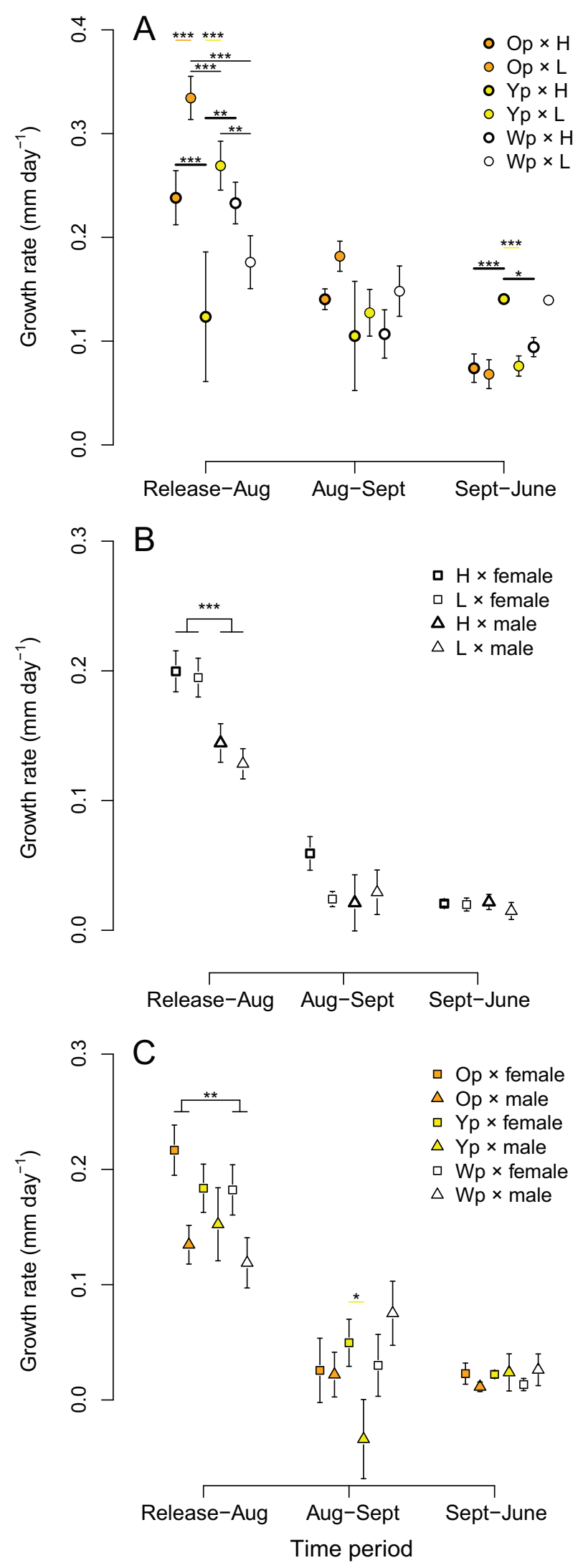

that adults in $\mathrm{H}$ humidity survived worse in Wp compared to Op and Yp populations $(Z=3.729, P<.001$ and $Z=$ 3.067, $P=.006$, respectively; fig. $4 C$ ), while no humidity differences existed in L, juveniles, and yearlings (fig. $4 A$, $4 B)$. The interactions CMF $\times \operatorname{sex}\left(\chi_{2}^{2}=8.790, P=.012\right)$ and humidity $\times \operatorname{sex}\left(\chi_{1}^{2}=6.302, P=.012\right)$ were also significant (table 1). Males survived worse in Wp populations compared to Op $\left(\chi_{1}^{2}=15.42, P<.001\right)$ and Yp $\left(\chi_{1}^{2}=\right.$ $11.64, P=.003)$ populations, and they survived better than females in Op populations $\left(\chi_{1}^{2}=8.81, P=.009\right)$. Moreover, in L humidity, males survived better than females $\left(\chi_{1}^{2}=10.11, P=.003\right)$, while no differences existed in $\mathrm{H}$ humidity $\left(\chi_{1}^{2}=0.18, P=.668\right)$. The interactions between humidity treatment, CMF, and male color morph ( $o$ and $w$ scores; $\chi_{1}^{2}<0.01, P=1$ ) and between treatments and male color morph were not significant (all $P>.5$ ), showing that reduced survival in $\mathrm{Wp}, \mathrm{H}$ humidity populations (fig. 4C) did not arise due to differential color morph survival.

\section{Reproductive Success}

A total of 71 females laid a clutch. Average clutch size was $5.37 \pm 0.16$ eggs, and 241 juveniles hatched successfully (i.e., were alive; males: $n=124$; females: $n=80$; undetermined sex: $n=37)$. We found no significant differences in clutch size among treatments or interactions with treatments (all $P>.570)$. Clutch size positively correlated with female SVL $\left(\chi_{1}^{2}=9.02, P=.003\right)$.

Offspring Traits. Offspring sex ratio was on average 0.61 (i.e., male biased) and was affected by $\operatorname{CMF}\left(\chi_{2}^{2}=6.30\right.$, $P=.043)$. Post hoc tests revealed male-biased sex ratios in Op and Yp populations and female-biased sex ratios in Wp populations $(Z=2.31, P=.05$ and $Z=2.33, P=$ .049 , respectively; fig. A3).

SVL of hatchlings was significantly affected by an interaction between humidity and CMF (table A5; fig. A4). Post hoc tests showed that in Op populations, hatchlings of mothers from $\mathrm{H}$ humidity were larger than those of mothers from L humidity $\left(0.91 \mathrm{~mm} ; \chi_{1}^{2}=5.75, P=.049\right)$. In L humidity, offspring of mothers living in Op populations were significantly shorter than those of mothers of $\mathrm{Wp}$ $\left(1.50 \mathrm{~mm} ; \chi_{1}^{2}=7.86, P=.025\right)$ or Yp $\left(1.40 \mathrm{~mm} ; \chi_{1}^{2}=\right.$ 11.77, $P=.004)$ populations. Males and females differed

Figure 2: Juvenile growth rate by color morph frequency (CMF; orange, yellow, and white predominance [Op, Yp, and $\mathrm{Wp}$, respectively]) and humidity treatment $(\mathrm{H}$ : high humidity; L: low humidity; $A$ ); yearling growth rate by humidity and sex $(B)$ and CMF and sex $(C)$ for each of the three time periods. Shown are means \pm SE. Horizontal bars depict main effects (sex and CMF differences) or post hoc contrasts, and asterisks indicate the level of statistical significance: for one asterisk, $P<.05$; for two asterisks, $P<.01$; for three asterisks, $P<.001$. 


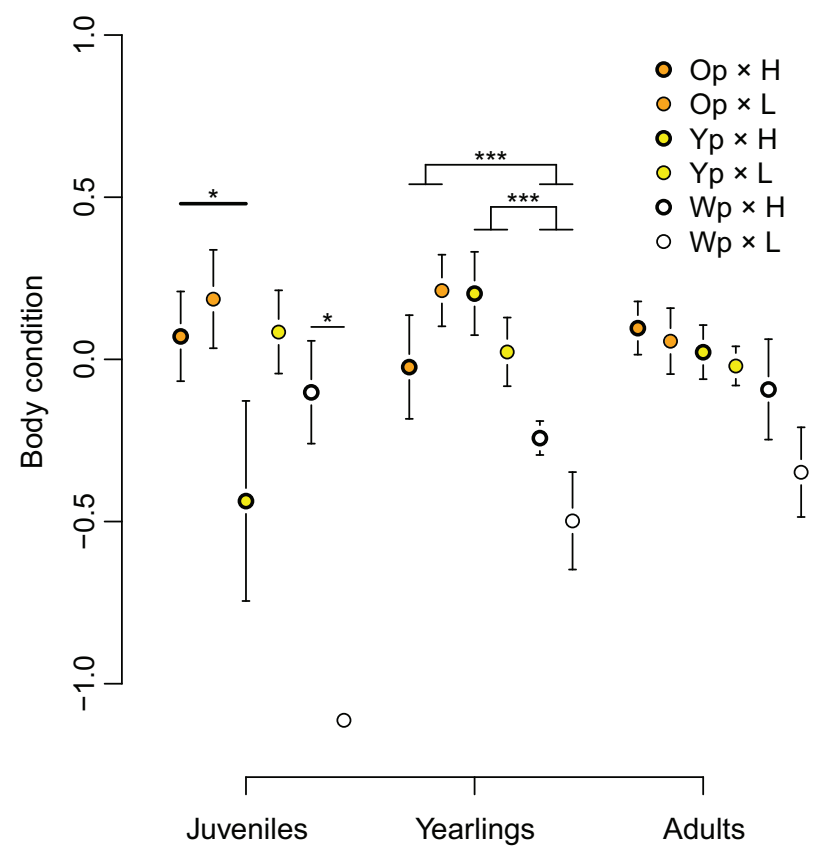

Figure 3: Final body condition of juveniles, yearlings, and adults by color morph frequency (CMF; orange, yellow, and white predominance [Op, Yp, and $\mathrm{Wp}$, respectively] are colored with their respective colors) and humidity treatment ( $\mathrm{H}$ : high humidity; L: low humidity). Means \pm SE are given. Horizontal bars depict significant main effects (CMF differences) or post hoc contrasts, and asterisks indicate statistical significance: for one asterisk, $P<.05$; for three asterisks, $P<.001$.

in size at hatching (table A5); females were on average 1.74 $\pm 0.98 \mathrm{~mm}$ longer than males irrespective of treatment. Additionally, Rclsize and hatching date were negatively correlated with the progeny's SVL, the latter showing that earlyhatching juveniles were larger than later-hatched juveniles.

Tail length at hatching was unaffected by treatments, but it differed between sexes (table A5). Males had $0.610 \pm$ 0.030 -mm-longer tails than females. Neither Rclsize nor hatching date affected tail length. Similarly, offspring body condition at hatching was unaffected by treatments, but it differed between sexes (table A5). Males exhibited higher body condition than females. Additionally, tail length and body condition at hatching positively correlated.

\section{Discussion}

Using an experimental approach, we tested whether and how environmental conditions and the genetic characteristics of a population affect important individual traits (i.e., traits that are closely tied to demographic parameters) and thereby the dynamics of populations (Bjørnstad and Hansen 1994). Our results reveal the effects of habitat humidity on juvenile growth (prediction 1) and the interactive effects of
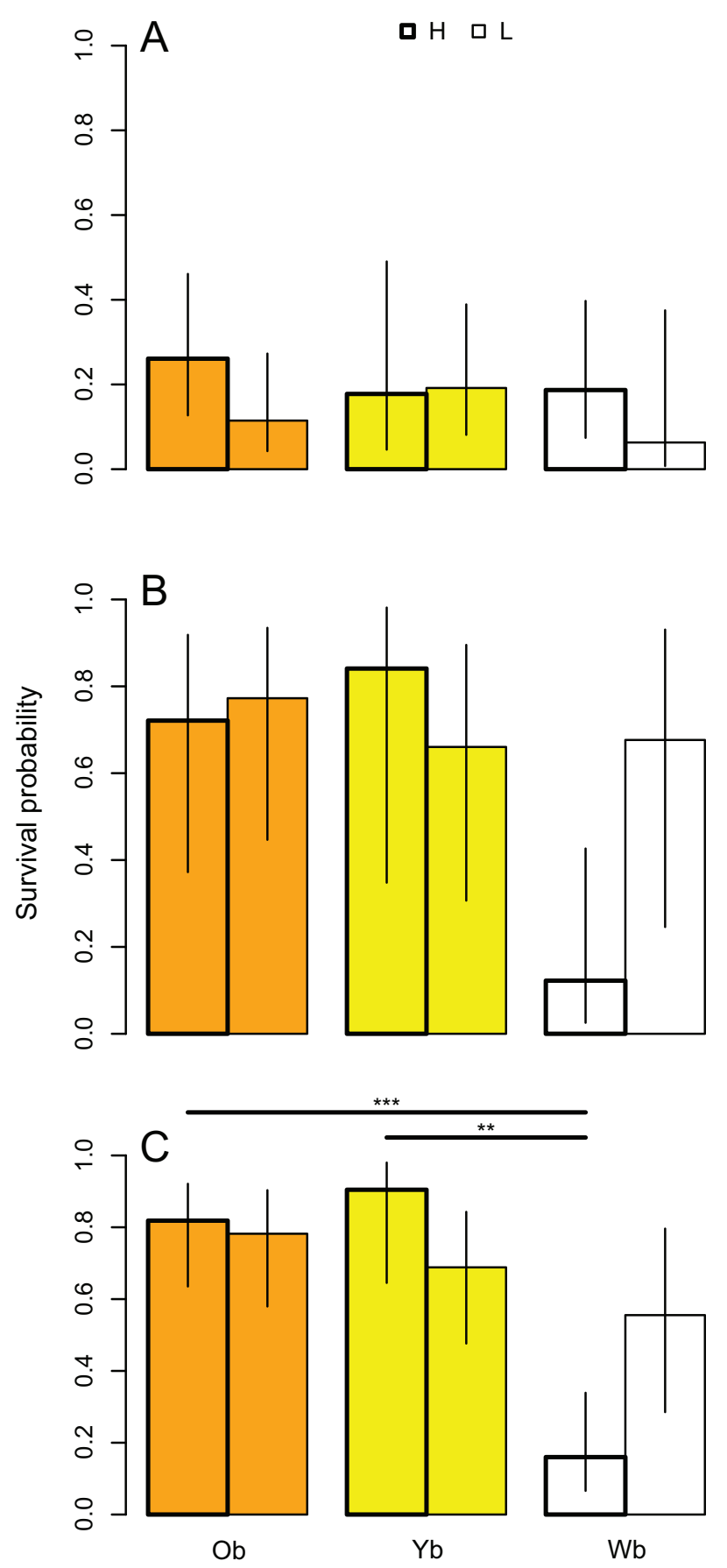

Figure 4: Annual survival probability by color morph frequency (orange, yellow, and white predominance [Op, Yp, and Wp, respectively]) and humidity ( $\mathrm{H}$ : high humidity; L: low humidity) of all three age classes: juveniles $(A)$, yearlings $(B)$, and adults $(C)$. Shown are mean expected survival probabilities $\pm 95 \%$ confidence interval. Horizontal bars depict post hoc contrasts, and asterisks indicate statistical significance: for two asterisks, $P<.01$; for three asterisks, $P<$ .001 . 
habitat humidity and adult color morph frequency on growth and body condition of juveniles and yearlings (prediction 2), pointing to treatment effects on inter-age class competition (prediction 3). We also found interactive effects on adult survival and delayed interactive treatment effects on offspring traits (prediction 4; table 1). These results show that abiotic environmental conditions and the genetic characteristics of the population are immediate and delayed (parentally derived) sources of intra- and inter-age class variation in lifehistory traits and thus that they influence the dynamics of populations (Lindström 1999; Bolnick et al. 2011).

Genetic variability (e.g., in terms of genotype diversity and frequency) is thought to favor population persistence and resilience via evolutionary rescue (Whiteley et al. 2015). Color polymorphic species have been considered to be less vulnerable against changes in selective regimes (e.g., resulting from climate change) on account of their higher genetic variability and enhanced evolutionary potential (Forsman et al. 2008). However, the genetic architecture of many color polymorphisms exhibits genome-wide linkage, where color is linked with many other traits, potentially constraining trait divergence (McKinnon and Pierotti 2010; Wellenreuther et al. 2014; Bolton et al. 2015). Moreover, traits linked with and traits unrelated to color morph are likely undergoing selection, and thus the role of the genetic characteristics of the population in population stability is unclear.

It has been suggested that genetic characteristics are less important to short-term population viability, although they might be crucial in the long term (Lande 1988). In contrast to this suggestion, here we experimentally demonstrate that environmental effects depend on the population's morph frequency and that their interaction affects life-history traits and demography and thus short-term population dynamics. For example, the effects of habitat humidity on adult survival depended on the morph frequency (table 1; fig. 4C). Under $\mathrm{H}$ humidity conditions, Wp populations showed reduced adult survival compared to Op and Yp populations. Moreover, increased humidity did not affect the survival of a specific color morph, which suggests that climate modifies the competitive environment of the population rather than the fate of a given morph (i.e., traitbased selection). Because juvenile mortality is characteristically high, recruitment alone usually cannot compensate a significant drop in adult survival, putting these populations at risk (Bestion et al. 2015). Thus, color morph frequency can help predict the impact of environmental change on local dynamics of Zootoca vivipara populations. Furthermore, neighboring natural populations of $Z$. vivipara often exhibit similar color morph frequencies (Sinervo et al. 2007) and thus may respond to environmental change in a similar way, affecting metapopulation dynamics. These results agree with earlier studies, which suggest that the genetic charac- teristics of the population influence its demographic trajectory (e.g., in butterflies [Hanski and Saccheri 2006], killifish [Leips et al. 2000], or moths [Nokelainen et al. 2013]), and thus they may be more relevant to short-term population dynamics than previously thought.

Our results also revealed plastic compensatory patterns (Charmantier et al. 2008), in line with flexible life-history strategies that allow one to compensate for immediate effects of adverse conditions later in life (Sorci et al. 1996; Lorenzon et al. 2001; Le Galliard et al. 2008, 2010). For instance, humidity $\times$ CMF effects on early growth of juveniles (i.e., from release to August) and on body condition change of yearlings were compensated over the course of the experiment. As a result, no interactive effects on final body size and final body condition existed (table 1). A priori, this points to a high adaptive potential and resilience against unfavorable environmental change. Additionally, treatments had delayed effects on offspring body size, an important determinant of age at maturation (Stearns 1992) and asymptotic body size (Fitze and Le Galliard 2008), the latter predicting reproductive success. Given that females were randomly distributed among treatments and enclosures and maintained in standardized humidity and CMF conditions previous to the start of the experiment, treatment effects cannot be attributed to previous environmental conditions. This suggests that mothers may prepare offspring for the conditions they will experience (Mousseau and Fox 1998; Meylan et al. 2012; Bestion et al. 2014), for instance, by adjusting offspring sex ratio (Maślak et al. 2010) or juvenile body size, representing another mechanism of delayed compensation (see Le Galliard et al. 2008).

Treatment effects also differed between sexes and age classes (table 1; figs. 1-4). Sex differences are in line with sex-specific selective pressures (Pilorge et al. 1987), alternative life-history strategies (Massot et al. 1992), and different environmental sensitivity between the sexes (Lindström 1999). In yearlings, humidity affected growth rates and final SVL of females but not of males (table 1; figs. 1, 2B), and no treatment $\times$ sex effects existed on growth rates and SVL in juveniles and adults. Smaller final SVL of yearling females in L humidity is in line with reduced food availability and variability in L humidity conditions (Ferguson 2004; Chikoski et al. 2006) and with slower growth rates induced by lower humidity per se (Lorenzon et al. 1999). Moreover, this sex-specific treatment effect is in line with higher energetic demands of females compared to males due to their larger body sizes (Hulbert and Else 2004), pointing to increased susceptibility to environmental conditions of females. Given that SVL affects the timing of recruitment, a key demographic parameter contributing to variation in population growth (Coulson et al. 2005), humidity effects on SVL of female yearlings directly affect population dynamics and sexual selection (Fitze and Le Galliard 2008). 
Interestingly, sex and morph frequency-dependent sex differences in growth were compensated over the course of the experiment in juveniles and yearlings, respectively. In contrast, males of all age classes survived better in L humidity populations than females, while no differences existed in $\mathrm{H}$ humidity. This indicates that in drier conditions, sex ratios of $Z$. vivipara populations will skew toward males due to higher male survival and later female recruitment, leading to an increase in male sexual harassment and reduced female survival and eventually to population collapse (Le Galliard et al. 2005b).

Differences in treatment effects among age classes agreed with the hierarchy of the inter-age class competition (adult dominance over yearlings and older age class dominance over juveniles; Pilorge et al. 1987; Lecomte et al. 1994) since adults were the least affected, while yearlings and juveniles were strongly affected by treatments (table 1). CMF effects arise through differences in competition between adult males and the other age classes or sex (note that only adult morph frequency differed among CMF treatments; the number of lizards and their SVL or BC did not), and thus treatment $\times$ age class effects are in line with dominance interactions based on resources, where the competitively superior individuals limit the energy intake of the competitively inferior individuals if the resources are limited (Nicholson 1954; Beckerman et al. 2003; De Roos and Persson 2003). CMF $\times$ humidity interactions thus reveal an interplay between ecological conditions and intra- (in adults) or inter-age class competition (Mugabo et al. 2010, 2011). More generally, demographic changes in age and sex structure (i.e., sex ratios) affect intra- and inter-age class competition and population effective size (Lande 1988), which can also importantly affect population dynamics and viability (Clutton-Brock and Parker 1995).

Since differences in humidity may lead to temperature changes (i.e., L humidity $\approx$ warmer temperatures; $\mathrm{H}$ humidity $\approx$ cooler temperatures), humidity effects may be potentially confounded with temperature. However, the relatively high ambient temperatures at the study site and the experimental design (all populations were exposed to the same humidity treatment length) minimized potential humidity treatment effects on temperature. Furthermore, previous experimental evidence in $Z$. vivipara (Bestion et al. 2015) has shown that warmer temperatures increase the pace of life, leading to faster growth, earlier reproductive onset, and lower survival, and our results importantly contrast those predictions. Namely, L humidity (i.e., potentially warmer temperatures) did not affect yearlings and juveniles at all, and $\mathrm{H}$ (rather than L) humidity decreased the survival of adults in Wp populations. Consequently, the hereobtained results cannot be attributed to an indirect effect of temperature.
In conclusion, here we experimentally show that population responses to environmental change depend on the population's color morph frequency, age structure, and sex structure, revealing their complexity. While some effects induced by environmental conditions were compensated through behavioral short-term adaptation (e.g., plastic compensation patterns of differences in initial growth), others may threaten population viability (e.g., alteration of demographic structure and morph frequency cycles). Since the genetic characteristics, age structure, and sex structure of a population generally vary over a species' distribution range (Corl et al. 2010; McLean and Stuart-Fox 2014), predicting species' responses to climatic change might be more challenging than previously thought (Parmesan 2006; Dawson et al. 2011; McMahon et al. 2011; Bellard et al. 2012; IPCC 2013). Our results suggest that a lack of data on the genetic characteristics and demographic structure of local populations may importantly compromise the conservation of biodiversity as well as the understanding of a species' evolutionary history.

\section{Acknowledgments}

We thank M. Peñalver-Alcázar, L. Ros Vicente, and A. M. Prieto for assistance in the field and L. M. San-Jose for providing background knowledge. C.R.D. was supported by the Spanish Ministry of Education (FPU program), grant AP2009-0350. M.C.B. was supported by a Ph.D. grant (JAEPre_09_01372) from the Consejo Superior de Investigaciones Científicas, cofinanced by the European Social Fund Project. Funds were provided by the Spanish Ministry of Education and Science (CGL2008-01522, CGL2012-32459, CGL2016-76918P to P.S.F.) and the Swiss National Science Foundation (PPOOP3_128375, PP00P3_152929/1 to P.S.F.). The capture and handling of lizards were conducted under the license provided by the Gobierno de Aragón (LC/ehv 24/2010/105 \& 106) and Gobierno de Navarra. The conducted study complies with current Spanish laws and Association for the Study of Animal Behaviour/Animal Behavior Society guidelines for the treatment of animals in behavioral research.

\section{Literature Cited}

Araújo, M. B., R. J. Whittaker, R. J. Ladle, and M. Erhard. 2005. Reducing uncertainty in projections of extinction risk from climate change. Global Ecology and Biogeography 14:529-538.

Arribas, O. J. 2009. Morphological variability of the CantabroPyrenean populations of Zootoca vivipara (Jacquin, 1787) with description of a new subspecies (Squamata: Sauria: Lacertidae). Herpetozoa 21:123-146.

Avery, R. A. 1975. Age-structure and longevity of common lizard (Lacerta vivipara) populations. Journal of Zoology 176:555-558. 
Bates, D., M. Maechler, B. Bolker, and S. Walker. 2013. lme4: linear mixed-effects models using Eigen and S4. R package version 1.0-4. http://CRAN.R-project.org/package $=$ lme 4 .

Bauwens, D. 1999. Life-history variation in lacertid lizards. Natura Croatica 8:239-252.

Beckerman, A. P., T. G. Benton, C. T. Lapsley, and N. Koesters. 2003. Talkin' 'bout my generation: environmental variability and cohort effects. American Naturalist 162:754-767.

Beckerman, A. P., T. G. Benton, E. Ranta, V. Kaitala, and P. Lundberg. 2002. Population dynamic consequences of delayed life-history effects. Trends in Ecology and Evolution 17:263-269.

Bellard, C., C. Bertelsmeier, P. Leadley, W. Thuiller, and F. Courchamp. 2012. Impacts of climate change on the future of biodiversity. Ecology Letters 15:365-377.

Benton, T. G., T. C. Cameron, and A. Grant. 2004. Population responses to perturbations: predictions and responses from laboratory mite populations. Lournal of Animal Ecology 73:983-995.

Benton, T. G., S. J. Plaistow, and T. N. Coulson. 2006. Complex population dynamics and complex causation: devils, details and demography. Proceedings of the Roval Society B 273:1173-1181.

Bertossa, R. C. 2011. Morphology and behaviour: functional links in development and evolution. I. Introduction. Philosophical Transactions of the Roval Society B 366:2056-2068.

Bestion, E., A. Teyssier, F. Aubret, J. Clobert, and J. Cote. 2014. Maternal exposure to predator scents: offspring phenotypic adjustment and dispersal. Proceedings of the Roval Society B 281: 20140701.

Bestion, E., A. Teyssier, M. Richard, J. Clobert, and J. Cote. 2015 Live fast, die young: experimental evidence of population extinction risk due to climate change. PLoS Biology 13:e1002281.

Bjørnstad, O. N., and T. F. Hansen. 1994. Individual variation and population dynamics. Oikos 69:167-171.

Bleu, J., J.-F. Le Galliard, P. S. Fitze, S. Meylan, J. Clobert, and M. Massot. 2013. Reproductive allocation strategies: a long-term study on proximate factors and temporal adjustments in a viviparous lizard. Oecologia 171:141-151.

Bolnick, D. I., P. Amarasekare, M. S. Araújo, R. Bürger, J. M. Levine, M. Novak, V. H. W. Rudolf, S. J. Schreiber, M. C. Urban, and D. Vasseur. 2011. Why intraspecific trait variation matters in community ecology. Trends in Ecology and Evolution 26:183-192.

Bolton, P. E., L. A. Rollins, and S. C. Griffith. 2015. The danger within: the role of genetic, behavioural and ecological factors in population persistence of colour polymorphic species. Molecular Ecology 24: 2907-2915.

Braña, F. 1996. Sexual dimorphism in lacertid lizards: male head increase vs. female abdomen increase? Oikos 75:511-523.

Breedveld, M. C., and P. S. Fitze. 2015. A matter of time: delayed mate encounter postpones mating window initiation and reduces the strength of female choosiness. Behavioral Ecology and Sociobiology 69:533-541.

Ceirans, A. 2007. Microhabitat characteristics for reptiles Lacerta agilis, Zootoca vivipara, Anguis fragilis, Natrix natrix, and Vipera berus in Latvia. Russian Journal of Herpetology 14:172-176.

Clobert, J., A. Oppliger, G. Sorci, B. Ernande, J. G. Swallow, and T. G. Jr. 2000. Trade-offs in phenotypic traits: endurance at birth, growth, survival, predation and susceptibility to parasitism in a lizard, Lacerta vivipara. Functional Ecology 14:675-684.

Clutton-Brock, T. H., and G. A. Parker. 1995. Sexual coercion in animal societies. Animal Behaviour 49:1345-1365.
Corl, A., A. R. Davis, S. R. Kuchta, and B. Sinervo. 2010. Selective loss of polymorphic mating types is associated with rapid phenotypic evolution during morphic speciation. Proceedings of the National Academv of Sciences of the USA 107:4254-4259.

Coulson, T., J. M. Gaillard, and M. Festa-Bianchet. 2005. Decomposing the variation in population growth into contributions from multiple demographic rates. Iournal of Animal Ecology 74:789801.

Charmantier, A., R. H. McCleery, L. R. Cole, C. Perrins, L. E. B. Kruuk, and B. C. Sheldon. 2008. Adaptive phenotypic plasticity in response to climate change in a wild bird population. Science 320:800-803.

Chikoski, J. M., S. H. Ferguson, and L. Meyer. 2006. Effects of water addition on soil arthropods and soil characteristics in a precipitationlimited environment. Acta Oecologica 30:203-211.

Dawson, T. P., S. T. Jackson, J. I. House, I. C. Prentice, and G. M. Mace. 2011. Beyond predictions: biodiversity conservation in a changing climate. Science 332:53-58.

De Roos, A. M., and L. Persson. 2003. Competition in size-structured populations: mechanisms inducing cohort formation and population cycles. Theoretical Population Biology 63:1-16.

Ergon, T., X. Lambin, and N. C. Stenseth. 2001. Life-history traits of voles in a fluctuating population respond to the immediate environment. Nature 411:1043-1045.

Ferguson, S. H. 2004. Does predation or moisture explain distance to edge distribution of soil arthropods? American Midland Naturalist 152:75-87.

Fitze, P. S., J. Cote, and J. Clobert. 2010. Mating order-dependent female mate choice in the poligynandrous common lizard Lacerta vivipara. Oecologia 162:331-341.

Fitze, P. S., J. Cote, L. M. San-Jose, S. Meylan, C. Isaksson, S. Andersson, J. M. Rossi, and J. Clobert. 2009. Carotenoid-based colours reflect the stress response in the common lizard. PLoS ONE 4:1-10.

Fitze, P. S., V. González Jimena, L. M. San-Jose, B. Heulin, and B. Sinervo. 2014. Frequency-dependent sexual selection with respect to offspring fitness returns is consistent with predictions from rock-paper-scissors dynamics in the European common lizard. Frontiers in Ecology and Evolution 2:77.

Fitze, P. S., and J.-F. Le Galliard. 2008. Operational sex ratio, sexual conflict and the intensity of sexual selection. Ecology Letters 11:432439.

Fitze, P. S., J.-F. Le Galliard, P. Federici, M. Richard, and J. Clobert. 2005. Conflict over multiple-partner mating between males and females of the polygynandrous common lizards. Evolution 59:24512459.

Forsman, A., J. Ahnesjo, S. Caesar, and M. Karlsson. 2008. A model of ecological and evolutionary consequences of color polymorphism. Ecology 89:34-40.

Grenot, C., and B. Heulin. 1990. Sur la plasticité ecophysiologique du lézard vivipare, Lacerta vivipara (Reptilia, Lacertidae). Bulletin de la Societe Herpetologique de France 54:1-22.

Grenot, C., B. Heulin, T. Pilorge, M. Khodadoost, A. Ortega, and Y. P. Mou. 1987. Water budget in some populations of the European common lizard, Lacerta vivipara Jacquin. Functional Ecology 1:131-138.

Hanski, I., and I. Saccheri. 2006. Molecular-level variation affects population growth in a butterfly metapopulation. PLoS Biology 4:719726. 
Heulin, B. 1985. Maturité sexuelle et âge à la première reproduction dans une population de plaine de Lacerta vivipara. Canadian Journal of Zoology 63:1773-1777.

Heulin, B., K. Osenegg, and D. Michel. 1994. Survie et incubation des oeufs dans deux populations ovipares de Lacerta vivipara. Amphibia-Reptilia 15:199-219.

Heulin, B., K. Osenegg-Leconte, and D. Michel. 1997. Demography of a bimodal reproductive species of lizard (Lacerta vivipara): survival and density characteristics of oviparous populations. Herpetologica 53:432-444.

Hoffmann, A. A., and C. M. Sgrò. 2011. Climate change and evolutionary adaptation. Nature 470:479-485.

Holm, S. 1979. A simple sequentially rejective multiple test procedure. Scandinavian Journal of Statistics 6:65-70.

Horváthová, T., C. R. Cooney, P. S. Fitze, T. A. Oksanen, D. Jelić, I. Ghira, T. Uller, and D. Jandzik. 2013. Length of activity season drives geographic variation in body size of a widely distributed lizard. Ecology and Evolution 3:2424-2442.

Hulbert, A. J., and P. L. Else. 2004. Basal metabolic rate: history, composition, regulation, and usefulness. Physiological and Biochemical Zoology 77:869-876.

IPCC (Intergovernmental Panel on Climate Change). 2013. Summary for policymakers. Pages 3-29 in T. F. Stocker, D. Qin, G.-K. Plattner, M. Tignor, S. K. Allen, J. Boschung, A. Nauels, Y. Xia, V. Bex, and P. M. Midgley, eds. Climate change 2013: the physical science basis. Working Group I Contribution to the Fifth Assessment Report of the Intergovernmental Panel on Climate Change. Cambridge University Press, Cambridge.

Lande, R. 1988. Genetics and demography in biological conservation. Science 241:1455-1460.

. 1993. Risks of population extinction from demographic and environmental stochasticity and random catastrophes. American Naturalist 142:911-927.

Lande, R., and S. Shannon. 1996. The role of genetic variation in adaptation and population persistence in a changing environment. Evolution 50:434-437.

Lecomte, J., J. Clobert, and M. Massot. 1992. Sex identification in juveniles of Lacerta vivipara. Amphibia-Reptilia 13:21-25.

Lecomte, J., J. Clobert, M. Massot, and R. Barbault. 1994. Spatial and behavioural consequences of a density manipulation in the common lizard. Ecoscience 1:300-310.

Le Galliard, J.-F., J. Cote, and P. S. Fitze. 2008. Lifetime and intergenerational fitness consequences of harmful male interactions for female lizards. Ecology 89:56-64.

Le Galliard, J.-F., P. S. Fitze, J. Cote, M. Massot, and J. Clobert. 2005a. Female common lizards (Lacerta vivipara) do not adjust their sex-biased investment in relation to the adult sex ratio. Journal of Evolutionary Biology 18:1455-1463.

Le Galliard, J.-F., P. S. Fitze, R. Ferrière, and J. Clobert. 2005b. Sex ratio bias, male aggression, and population collapse in lizards. Proceedings of the National Academy of Sciences of the USA 102:18231-18236.

Le Galliard, J.-F., O. Marquis, and M. Massot. 2010. Cohort variation, climate effects and population dynamics in a short-lived lizard. Journal of Animal Ecology 79:1296-1307.

Le Galliard, J.-F., M. Massot, M. M. Landys, S. Meylan, and J. Clobert. 2006. Ontogenic sources of variation in sexual size dimorphism in a viviparous lizard. Journal of Evolutionary Biology 19:690-704.
Leips, J., J. Travis, and F. H. Rodd. 2000. Genetic influences on experimental population dynamics of the least killifish. Ecological Monographs 70:289-309.

Lindström, J. 1999. Early development and fitness in birds and mammals. Trends in Ecology and Evolution 14:343-348.

Lindström, J., and H. Kokko. 2002. Cohort effects and population dynamics. Ecology Letters 5:338-344.

Lorenzon, P., J. Clobert, and M. Massot. 2001. The contribution of phenotypic plasticity to adaptation in Lacerta vivipara. Evolution 55:392-404.

Lorenzon, P., J. Clobert, A. Oppliger, and H. John-Alder. 1999. Effect of water constraint on growth rate, activity and body temperature of yearling common lizard (Lacerta vivipara). Oecologia 118:423430.

Marquis, O., M. Massot, and J.-F. Le Galliard. 2008. Intergenerational effects of climate generate cohort variation in lizard reproductive performance. Ecology 89:2575-2583.

Maślak, R., Ł. Paśko, J. Kusznierz, and M. Moska. 2010. Sex ratio in population of Lacerta vivipara (Jacquin, 1787) (Sauria, Lacertidae) in a lowland habitat of the vicinity of Wrocław, SW Poland. Zeszyty Naukowe Uniwersytetu Przyrodniczego we Wrocławiu: Biologia i Hodowla Zwierzat 60:97-106.

Massot, M., J. Clobert, L. Montes-Poloni, C. Haussy, J. Cubo, and S. Meylan. 2011. An integrative study of ageing in a wild population of common lizards. Functional Ecology 25:848-858.

Massot, M., J. Clobert, T. Pilorge, J. Lecomte, and R. Barbault. 1992. Density dependence in the common lizard: demographic consequences of a density manipulation. Ecology 73:1742-1756.

McKinnon, J. S., and M. E. R. Pierotti. 2010. Colour polymorphism and correlated characters: genetic mechanisms and evolution. $\underline{\mathrm{Mo}-}$ lecular Ecology 19:5101-5125.

McLean, C. A., and D. Stuart-Fox. 2014. Geographic variation in animal colour polymorphisms and its role in speciation. Biological Reviews of the Cambridge Philosophical Society 89:860-873.

McMahon, S. M., S. P. Harrison, W. S. Armbruster, P. J. Bartlein, C. M. Beale, M. E. Edwards, J. Kattge, G. Midgley, X. Morin, and I. C. Prentice. 2011. Improving assessment and modelling of climate change impacts on global terrestrial biodiversity. Trends in Ecology and Evolution 26:249-259.

Melbourne, B. A., and A. Hastings. 2008. Extinction risk depends strongly on factors contributing to stochasticity. Nature 454:100103.

Meylan, S., D. B. Miles, and J. Clobert. 2012. Hormonally mediated maternal effects, individual strategy and global change. Philosophical Transactions of the Roval Societv B 367:1647-1664.

Milá, B., Y. Surget-Groba, B. Heulin, A. Gosa, and P. S. Fitze. 2013. Multilocus phylogeography of the common lizard Zootoca vivipara at the Ibero-Pyrenean suture zone reveals lowland barriers and high-elevation introgression. BMC Evolutionary Biology 13: 192.

Mousseau, T. A., and C. W. Fox. 1998. The adaptive significance of maternal effects. Trends in Ecology and Evolution 13:403-407.

Mugabo, M., O. Marquis, S. Perret, and J.-F. Le Galliard. 2010. Immediate and delayed life history effects caused by food deprivation early in life in a short-lived lizard. Journal of Evolutionary Biology 23:1886-1898.

. 2011. Direct and socially-mediated effects of food availability late in life on life-history variation in a short-lived lizard. Oecologia 166:949-960. 
Nicholson, A. J. 1954. An outline of the dynamics of animal populations. Australian Journal of Zoology 2:9-65.

Nokelainen, O., C. Lindstedt, and J. Mappes. 2013. Environmentmediated morph-linked immune and life-history responses in the aposematic wood tiger moth. Iournal of Animal Ecology 82:653-662.

Pacifici, M., W. B. Foden, P. Visconti, J. E. M. Watson, S. H. M. Butchart, K. M. Kovacs, B. R. Scheffers, et al. 2015. Assessing species vulnerability to climate change. Nature Climate Change 5: 215-224.

Parmesan, C. 2006. Ecological and evolutionary responses to recent climate change. Annual Review of Ecology, Evolution, and Systematics 37:637-669.

Peñalver-Alcázar, M., P. Aragón, M. C. Breedveld, and P. S. Fitze. 2016. Microhabitat selection in the common lizard: implications of biotic interactions, age, sex, local processes and model transferability among populations. Ecology and Evolution 6:3594-3607.

Pertoldi, C., R. Bijlsma, and V. Loeschcke. 2007. Conservation genetics in a globally changing environment: present problems, paradoxes and future challenges. Biodiversity and Conservation 16 4147-4163.

Pilorge, T. 1987. Density size, structure, and reproductive characteristics of 3 populations of Lacerta vivipara (Sauria, Lacertidae). Herpetologica 43:345-356.

Pilorge, T., J. Clobert, M. Massot, J. J. van Gelder, H. Strijbosch, and P. J. M. Bergers. 1987. Life history variations according to sex and age in Lacerta vivipara. Pages 311-315 in J. J. van Gelder, H. Strijbosch, and P. J. M. Bergers, eds. Proceedings of the 4th Ordinary General Meeting of the Societas Europaea Herpetologica. Societas Europaea Herpetologica, Faculty of Sciences, Nijmegen, Netherlands.

Pinheiro, J., D. Bates, S. DebRoy, D. Sarkar, and R Core Team. 2013. nlme: linear and nonlinear mixed effects models. R package version 3.1-108. http://CRAN.R-project.org/package $=$ nlme.

Roig, J. M., M. A. Carretero, and G. A. Llorente. 2000. Reproductive cycle in a Pyrenean oviparous population of the common lizard (Zootoca vivipara). Netherlands Journal of Zoology 50:15-27.

Romero-Diaz, C., M. Breedveld, and P. S. Fitze. 2017. Data from: Climate effects on growth, body condition, and survival depend on the genetic characteristics of the population. American Naturalist, Dryad Digital Repository, http://dx.doi.org/10.5061/dryad .$k 8776$.

San-Jose, L. M., F. Granado-Lorencio, and P. S. Fitze. 2012. Dietary lipids reduce the expression of carotenoid-based coloration in Lacerta vivipara. Functional Ecology 26:646-656.

San-Jose, L. M., F. Granado-Lorencio, B. Sinervo, and P. S. Fitze. 2013. Iridophores and not carotenoids account for chromatic variation of carotenoid-based coloration in common lizards (Lacerta vivipara). American Naturalist 181:396-409.
San-Jose, L. M., M. Peñalver-Alcázar, K. Huyghe, M. C. Breedveld, and P. S. Fitze. 2016. Inter-class competition in stage-structured populations: effects of adult density on life-history traits of adult and juvenile common lizards. Oecologia 182:1063-1074.

San-Jose, L. M., M. Peñalver-Alcázar, B. Milá, V. Gonzalez-Jimena, and P. S. Fitze. 2014. Cumulative frequency-dependent selective episodes allow for rapid morph cycles and rock-paper-scissors dynamics in species with overlapping generations. Proceedings of the Roval Society B 281:20140976.

Sgrò, C. M., A. J. Lowe, and A. A. Hoffmann. 2011. Building evolutionary resilience for conserving biodiversity under climate change. Evolutionary Applications 4:326-337.

Sinclair, S. J., M. D. White, and G. R. Newell. 2010. How useful are species distribution models for managing biodiversity under future climates? Ecology and Society 15:8.

Sinervo, B., J. Clobert, D. B. Miles, A. McAdam, and L. T. Lancaster. 2008. The role of pleiotropy vs. signaller-receiver gene epistasis in life history trade-offs: dissecting the genomic architecture of organismal design in social systems. Heredity 101:197-211.

Sinervo, B., B. Heulin, Y. Surget-Groba, J. Clobert, D. B. Miles, A. Corl, A. Chaine, and A. Davis. 2007. Models of density-dependent genic selection and a new rock-paper-scissors social system. American Naturalist 170:663-680.

Sinervo, B., and C. M. Lively. 1996. The rock-paper-scissors game and the evolution of alternative male strategies. Nature 380:240 243.

Sinervo, B., and E. Svensson. 2002. Correlational selection and the evolution of genomic architecture. Heredity 89:329-338.

Sorci, G., J. Clobert, and S. Belichon. 1996. Phenotypic plasticity of growth and survival in the common lizard Lacerta vivipara. nal of Animal Ecology 65:781-790.

Stearns, S. C. 1992. The evolution of life histories. Oxford University Press, Oxford.

Visser, M. E. 2008. Keeping up with a warming world; assessing the rate of adaptation to climate change. Proceedings of the Roval Society B 275:649-659.

Wellenreuther, M., E. I. Svensson, and B. Hansson. 2014. Sexual selection and genetic colour polymorphisms in animals. Molecular Ecology 23:5398-5414.

Whiteley, A. R., S. W. Fitzpatrick, W. C. Funk, and D. A. Tallmon. 2015. Genetic rescue to the rescue. Trends in Ecology and Evolution 30:42-49.

Zuur, A. F., E. N. Ieno, N. J. Walker, A. A. Saveliev, and G. M. Smith. 2009. Mixed effects models and extensions in ecology with R. Springer, New York.

Associate Editor: Jeff Leips Editor: Judith L. Bronstein 